\title{
Cancer risk related to low-dose ionizing radiation from cardiac imaging in patients after acute myocardial infarction
}

\author{
Mark J. Eisenberg MD MPH, Jonathan Afilalo MD MSc, Patrick R. Lawler MD, Michal Abrahamowicz PhD, \\ Hugues Richard MSc, Louise Pilote MD MPH PhD
}

See related commentary by Mercuri and colleagues, page 413

Competing interests: None declared.

This article has been peer reviewed.

Correspondence to:

Dr. Louise Pilote,

louise.pilote@mcgill.ca

CMAJ 2011. DOI:10.1503

/cmaj.100463

\section{- Abstract}

Background: Patients exposed to low-dose ionizing radiation from cardiac imaging and therapeutic procedures after acute myocardial infarction may be at increased risk of cancer.

Methods: Using an administrative database, we selected a cohort of patients who had an acute myocardial infarction between April 1996 and March 2006 and no history of cancer. We documented all cardiac imaging and therapeutic procedures involving low-dose ionizing radiation. The primary outcome was risk of cancer. Statistical analyses were performed using a time-dependent Cox model adjusted for age, sex and exposure to lowdose ionizing radiation from noncardiac imaging to account for work-up of cancer.

Results: Of the 82861 patients included in the cohort, $77 \%$ underwent at least one cardiac imaging or therapeutic procedure involving low-dose ionizing radiation in the first year after acute myocardial infarction. The cumulative exposure to radiation from cardiac procedures was 5.3 milliSieverts (mSv) per patientyear, of which $84 \%$ occurred during the first year after acute myocardial infarction. A total of 12020 incident cancers were diagnosed during the follow-up period. There was a dosedependent relation between exposure to radiation from cardiac procedures and subsequent risk of cancer. For every $10 \mathrm{mSv}$ of low-dose ionizing radiation, there was a $3 \%$ increase in the risk of age- and sex-adjusted cancer over a mean follow-up period of five years (hazard ratio 1.003 per millisievert, $95 \%$ confidence interval 1.002-1.004).

Interpretation: Exposure to low-dose ionizing radiation from cardiac imaging and therapeutic procedures after acute myocardial infarction is associated with an increased risk of cancer.
$\mathrm{S}$ tudies involving atomic bomb survivors have documented an increased incidence of malignant neoplasm related to the radiation exposure. ${ }^{1-4}$ Survivors who were farther from the epicentre of the blast had a lower incidence of cancer, whereas those who were closer had a higher incidence. ${ }^{5}$ Similar risk estimates have been reported among workers in nuclear plants. ${ }^{6}$ However, little is known about the relation between exposure to low-dose ionizing radiation from medical procedures and the risk of cancer.

In the past six decades since the atomic bomb explosions, most individuals worldwide have had minimal exposure to ionizing radiation. However, the recent increase in the use of medical imaging and therapeutic procedures involving low-dose ionizing radiation has led to a growing concern that individual patients may be at increased risk of cancer. ${ }^{7-12}$ Whereas strict regulatory control is placed on occupational expo- sure at work sites, no such control exists among patients who are exposed to such radiation. ${ }^{13-16}$

It is not only the frequency of these procedures that is increasing. Newer types of imaging procedures are using higher doses of low-dose ionizing radiation than those used with more traditional procedures. ${ }^{8,11}$ Among patients being evaluated for coronary artery disease, for example, coronary computed tomography is increasingly being used. This test may be used in addition to other tests such as nuclear scans, coronary angiography and percutaneous coronary intervention, each of which exposes the patient to lowdose ionizing radiation. ${ }^{12,17-21}$ Imaging procedures provide information that can be used to predict the prognosis of patients with coronary artery disease. Since such predictions do not necessarily translate into better clinical outcomes, ${ }^{8,12}$ the prognostic value obtained from imaging procedures using low-dose ionizing radiation needs to be balanced against the potential for risk. 
Authors of several studies have estimated that the risk of cancer is not negligible among patients exposed to low-dose ionizing radiation..$^{22-27}$ To our knowledge, none of these studies directly linked cumulative exposure and cancer risk. We examined a cohort of patients who had acute myocardial infarction and measured the association between low-dose ionizing radiation from cardiac imaging and therapeutic procedures and the risk of cancer.

\section{Methods}

\section{Patient population and data sources}

The hospital discharge summary database in Quebec (Med-Echo), which includes information on all hospital admissions in the province, was used to create a retrospective cohort of all patients admitted to hospital for the first time with acute myocardial infarction between Apr. 1, 1996, and Mar. 31, 2006. Using the patients' unique encrypted health insurance numbers, we linked these data to data from the Régie de l'Assurance Maladie du Québec (RAMQ) database. Information on the patients' vital status was obtained from the Med-Echo and RAMQ databases. Ascertainment of vital status has been validated in previous studies. ${ }^{28} \mathrm{We}$ included patients if their principal diagnosis on admission was acute myocardial infarction (code 410 in the 9th revision of the International Classification of Diseases and codes I21 and I22 in the 10th revision). The cohort construction has been previously described. ${ }^{28}$

We excluded patients if they had evidence of a prior diagnosis of cancer in the year before and the year after the admission date. We defined such evidence as (a) admission to hospital with a primary diagnosis of cancer, (b) a non-cancerrelated admission with cancer listed as a secondary diagnosis, (c) any outpatient visit with a diagnosis of cancer and (d) any in- or outpatient visit billed by an oncologist, regardless of the diagnosis.

The final cohort comprised 82861 patients.

\section{Radiation exposure}

The patients' records were examined for any cardiac radiologic procedures for diagnostic or therapeutic purposes after the acute myocardial infarction. We obtained these data by capturing physician billing codes for these procedures from the RAMQ database. The procedures of interest (and their average effective radiation dose in milliSieverts) were myocardial perfusion imaging $(15.6 \mathrm{mSv})$, diagnostic cardiac catheterization $(7.0 \mathrm{mSv})$, percutaneous coronary intervention $(15.0 \mathrm{mSv})$ and cardiac resting ventricu- lography (7.8 mSV). These estimated doses were obtained from previous reports. ${ }^{7,29}$

Patients were divided into five groups according to their level of exposure to low-dose ionizing radiation after acute myocardial infarction (no exposure [reference group], > $0-\leq 10 \mathrm{mSv}$, $>10-\leq 20 \mathrm{mSv},>20-\leq 30 \mathrm{mSv}$ and $>30 \mathrm{mSv}$ ).

\section{Diagnosis of cancer}

Follow-up for incident cancers began one year after the index admission related to acute myocardial infarction. Because of the latency between exposure to low-dose ionizing radiation and the development of cancer, a time lag of one year was added to the time of each exposure. Therefore, an incident cancer could be attributed to an exposure to radiation only if the cancer was diagnosed at least one year later. This time lag minimized the risk of spurious associations between low-dose ionizing radiation and cancer diagnosed soon thereafter. It also decreased the risk of work-up bias (imaging tests ordered in the diagnostic work-up of cancer, notwithstanding that cardiac imaging tests are seldom performed as a diagnostic work-up for cancer).

Cancer diagnoses were identified on the basis of codes from the 9th and 10th revisions of the International Classification of Diseases. All diagnostic codes from hospital admissions and outpatient visits were surveyed. A patient was considered to have cancer if at least one diagnostic code for cancer was recorded during follow-up in any of the following settings: (a) admission to hospital with a primary diagnosis of cancer, (b) a noncancer-related admission with cancer listed as a secondary diagnosis and (c) any outpatient visit with a cancer diagnosis.

\section{Statistical analysis}

We compared the clinical characteristics of patients with respect to their exposure to low-dose ionizing radiation from cardiac imaging or therapeutic procedures. In time-dependent Cox proportional hazards models, we explored the possible independent association between such exposure and risk of cancer. The following variables were adjusted for in the models: age, sex and exposure to low-dose ionizing radiation from noncardiac procedures. Variables for exposure to radiation from cardiac and noncardiac procedures were included both as continuous variables centred on the mean and as binary variables for exposure status. We centred all continuous variables for radiation exposure by subtracting their respective means from the original values for all patients exposed and attributing zero for those not exposed. In such a model, the coefficient of the continuous variable provides 
an estimate of the quantitative effect of this variable among those exposed to radiation only. ${ }^{30}$ The relation between continuous variables included in the model and the outcome was evaluated for linearity.

Sensitivity analyses were performed to explore different time lags (one, three and five years) between exposure to low-dose ionizing radiation and ascertainment of incident cancer, as well as truncated follow-up periods (one, two and three years) to ensure that the incident cancers were not occurring too soon after acute myocardial infarction or exposure to radiation.

\section{Results}

Table 1 shows the clinical characteristics of the 82861 patients stratified by their level of exposure to low-dose ionizing radiation from cardiac imaging and therapeutic procedures in the first year after acute myocardial infarction. The median age was 63.2 years (interquartile range 53.1-74.0), and $31.7 \%$ were women. In general, the exposure groups differed little with respect to clinical characteristics. Patients with higher levels of exposure tended to be younger males with fewer comorbidities. The level of exposure was higher among patients whose treating physician was a cardiologist than among those whose treating physician was a general practitioner. There was no consistent relation between exposure to radiation from cardiac procedures and exposure to radiation from noncardiac procedures.

The cumulative exposure to low-dose ionizing radiation from all cardiac procedures was $5.3 \mathrm{mSv}$ per patient-year, of which $84 \%$ occurred during the first year after acute myocardial infarction. Table 2 shows the frequency distribution of the cardiac procedures performed in the first year after acute myocardial infarction: $33.8 \%$ of patients had at least one myocardial perfusion imaging test, $40.7 \%$ had at least one percutaneous coronary intervention, $10.6 \%$ had at least one cardiac resting ventriculography, and $31.1 \%$ had at least one diagnostic cardiac catheterization not followed by percutaneous coronary intervention. Invasive procedures (diagnostic cardiac catheterization and percutaneous coronary intervention) accounted for $63.9 \%$ of the radiation from cardiac procedures.

Table 3 shows the frequency distribution of the 12020 incident cancers that were detected during follow-up, by site of cancer. There was a wide distribution, although cancers affecting the

Table 1: Characteristics of patients according to their level of exposure to low-dose ionizing radiation from cardiac imaging and therapeutic procedures in the first year after acute myocardial infarction

\begin{tabular}{|c|c|c|c|c|c|c|}
\hline \multirow[b]{2}{*}{ Characteristic } & \multicolumn{6}{|c|}{ Level of exposure; $\%$ of patients* } \\
\hline & $\begin{array}{c}\text { None } \\
n=19039\end{array}$ & $\begin{array}{c}>0 \text { to } \leq 10 \mathrm{mSv} \\
n=12331\end{array}$ & $\begin{array}{c}>10 \text { to } \leq 20 \mathrm{mSv} \\
n=25310\end{array}$ & $\begin{array}{c}>20 \text { to } \leq 30 \mathrm{mSv} \\
n=11091\end{array}$ & $\begin{array}{l}>30 \mathrm{mSv} \\
n=15090\end{array}$ & $\begin{array}{c}\text { Total } \\
n=82861\end{array}$ \\
\hline Age, yr, median (IQR) & $72.2(57.4-82.5)$ & $63.8(54.0-73.0)$ & $61.0(52.1-71.5)$ & $61.9(52.8-71.5)$ & $59.5(51.5-69.0)$ & $63.2(53.1-74.0)$ \\
\hline Sex, male & 59.5 & 68.9 & 71.6 & 70.9 & 71.6 & 68.3 \\
\hline \multicolumn{7}{|l|}{ Treating physician } \\
\hline General practitioner & 50.9 & 42.9 & 37.8 & 39.3 & 38.8 & 41.9 \\
\hline Cardiologist & 38.9 & 46.0 & 53.8 & 51.2 & 52.8 & 48.7 \\
\hline Hypertension & 32.9 & 35.3 & 33.7 & 33.9 & 34.2 & 33.9 \\
\hline Diabetes mellitus & 21.1 & 22.7 & 18.5 & 22.2 & 20.7 & 20.6 \\
\hline Heart failure & 20.2 & 16.0 & 11.7 & 15.3 & 13.3 & 15.0 \\
\hline Arrhythmia & 17.5 & 14.1 & 14.0 & 15.5 & 15.4 & 15.3 \\
\hline Chronic renal failure & 9.5 & 5.1 & 4.6 & 5.2 & 4.4 & 5.8 \\
\hline $\begin{array}{l}\text { Cerebrovascular } \\
\text { disease }\end{array}$ & 6.6 & 4.6 & 3.1 & 3.6 & 3.1 & 4.2 \\
\hline Acute renal failure & 4.4 & 2.5 & 2.1 & 2.4 & 2.1 & 2.7 \\
\hline Pulmonary edema & 1.3 & 1.1 & 0.5 & 0.7 & 0.5 & 0.8 \\
\hline Shock & 0.6 & 0.8 & 0.8 & 1.0 & 1.0 & 0.8 \\
\hline $\begin{array}{l}\text { Low-dose ionizing } \\
\text { radiation from } \\
\text { noncardiac procedures, } \\
\text { mSv, mean (SD) }\end{array}$ & $1.26(4.05)$ & $1.94(6.09)$ & $1.46(4.84)$ & $1.75(5.55)$ & $1.90(5.84)$ & $1.61(5.18)$ \\
\hline
\end{tabular}


abdomen/pelvis and thorax were the most common, accounting for about two-thirds of the cancers.

Figure 1 shows the relation between the cumulative exposure to low-dose ionizing radiation from cardiac procedures after acute myocardial infarction and the risk of cancer during the followup period. Cumulative exposure from cardiac procedures was an independent predictor of incident cancer (hazard ratio [HR] 1.003 per milliSievert, $95 \%$ confidence interval [CI] 1.002-1.004). For every $10 \mathrm{mSv}$ of radiation, there was a $3 \%$ increase in risk of age- and sex-adjusted cancer over a mean follow-up of 5.0 years.

When stratified by sex, the adjusted HR for incident cancer was 1.005 (95\% CI 1.003-1.007) among women and 1.002 (95\% CI 1.001-1.003) among men exposed to low-dose ionizing radiation. The interaction term for sex and radiation exposure was added to the multivariable Cox model and was found to be statistically significant $(p<0.001)$.

In the sensitivity analyses of the effect of different time lags on estimates of cancer risk, time lags of one, three and five years yielded similar results as those from the primary analysis. In the sensitivity analysis of the effect of different truncated follow-up periods, cumulative exposure to radiation from cardiac procedures was no longer a significant predictor of incident cancer when follow-up was truncated to one or two years. This finding is not surprising given that the link between exposure to low-dose ionizing radiation and incident cancer in such a short period is assumed to be biologically implausible.

\section{Interpretation}

We found a relation between the cumulative exposure to low-dose ionizing radiation from car- diac imaging and therapeutic procedures after acute myocardial infarction, and the risk of incident cancer. Although most patients were exposed to low or moderate levels of radiation, a substantial group were exposed to high levels and in general tended to be younger male patients with fewer comorbidities.

Previous studies have shown increased rates of use of imaging tests and therapeutic proced ures involving low-dose ionizing radiation in North America. ${ }^{7-12}$ This trend is particularly evident among patients with known or suspected coronary artery disease. There has been a marked increase in the number of imaging tests used to screen for this disease, including computed tomography angiography and radioisotope nuclear scans. In many centres, these types of tests have supplanted earlier tests that do not use radiation, such as exercise treadmill and stress echocardiography. ${ }^{12,17,21,31,32}$ Magnetic resonance imaging of the coronary arteries does not use radiation, but it is not being used as extensively as computed tomography angiography.

Although there is a paucity of data in the literature, our results are generally consistent with prior

Table 3: Frequency of 12020 incident cancers, by site

\begin{tabular}{|lrr|}
\hline Site & $\begin{array}{c}\text { No. (\%) of } \\
\text { incident cancers* }\end{array}$ \\
\hline Abdomen and pelvis & 5039 & $(41.9)$ \\
\hline Thorax (including breast cancer) & 3216 & $(26.8)$ \\
\hline Bone, soft tissue and skin & 2642 & $(22.0)$ \\
\hline Head and neck & 1085 & $(9.0)$ \\
\hline Hematologic & 987 & $(8.2)$ \\
\hline $\begin{array}{l}\text { *The total number is greater than } 12020 \text { because the cancers } \\
\text { are not mutually exclusive. }\end{array}$ & \\
\hline
\end{tabular}

Table 2: Frequency of cardiac imaging and therapeutic procedures in the first year after acute myocardial infarction

\begin{tabular}{|c|c|c|c|c|c|}
\hline \multirow[b]{2}{*}{ Procedure } & \multirow{2}{*}{$\begin{array}{l}\text { Mean effective } \\
\text { radiation dose, mSv }\end{array}$} & \multicolumn{3}{|c|}{$\begin{array}{l}\text { No. of tests performed; } \\
\% \text { of patients }\end{array}$} & \multirow{2}{*}{$\begin{array}{l}\% \text { of all low-dose } \\
\text { ionizing radiation } \\
\text { from cardiac imaging }\end{array}$} \\
\hline & & 0 & 1 & $\geq 2$ & \\
\hline Myocardial perfusion imaging & 15.6 & 66.3 & 29.4 & 4.4 & 29.9 \\
\hline $\begin{array}{l}\text { Percutaneous coronary } \\
\text { intervention* }\end{array}$ & 15.0 & 59.3 & 36.3 & 4.4 & 40.3 \\
\hline Cardiac resting ventriculography $\dagger$ & 7.8 & 89.4 & 9.7 & 0.9 & $6.3 \ddagger$ \\
\hline Diagnostic cardiac catheterization & 7.0 & 68.9 & 29.1 & 2.0 & 23.6 \\
\hline \multicolumn{6}{|c|}{$\begin{array}{l}\text { Note: } \mathrm{mSv}=\text { millisieverts (unit of measurement for radiation exposure). } \\
\text { *In Quebec, only percutaneous coronary intervention is billed when both a catheterization and a percutaneous coronary } \\
\text { intervention are done at the same time. This has been incorporated in the estimation of radiation dose. } \\
\text { tOne-year rates decreased from } 18 \% \text { to } 4 \% \text { during } 1996-2007 \text {. } \\
\text { fProportion is the average over a } 10 \text {-year period. }\end{array}$} \\
\hline
\end{tabular}


estimates of the risk of cancer associated with exposure to low-dose ionizing radiation. Specifically, the US Scoliosis Cohort Study involving young patients exposed to serial radiographic studies showed a relative risk of 1.6 for breast cancer for an average dose of $108 \mathrm{mSV}^{33}$ (extrapolation from our model generated an HR of 1.353 for all cancers for this same dose). The Japanese Life-Span Study involving atomic bomb survivors showed a relative risk of 1.1-1.2 for solid cancers for an average dose of $200 \mathrm{mSv}^{3}$ (HR 1.751 in extrapolation from our model). A pooled analysis of data for children exposed to external radiation showed a relative risk of 2.5 for thyroid cancer for an average dose of $50 \mathrm{mSv}^{34}$ (HR 1.150 among adults in extrapolation from our model). The higher effect among children is thought to be due to higher radiation sensitivity at a lower age.
It has been argued that patients who undergo frequent testing involving low-dose ionizing radiation tend to be older patients who are more likely to experience an adverse outcome related to their primary disease (e.g., coronary artery disease) rather than a radiation-related cancer. In our cohort, the median age was 63.2 years, and younger patients were more likely to be exposed to higher doses of radiation. Although mortality is increased among patients with acute myocardial infarction, disease-specific mortality has been decreasing since the 1960s. . $^{3,36}$ For the average patient surviving an acute myocardial infarction, life expectancy is substantial. ${ }^{36,37}$ Our results suggest that exposure to low-dose ionizing radiation directly affects the likelihood of cancer. Although these patients most likely will die of cardiac-related causes, the increased exposure to

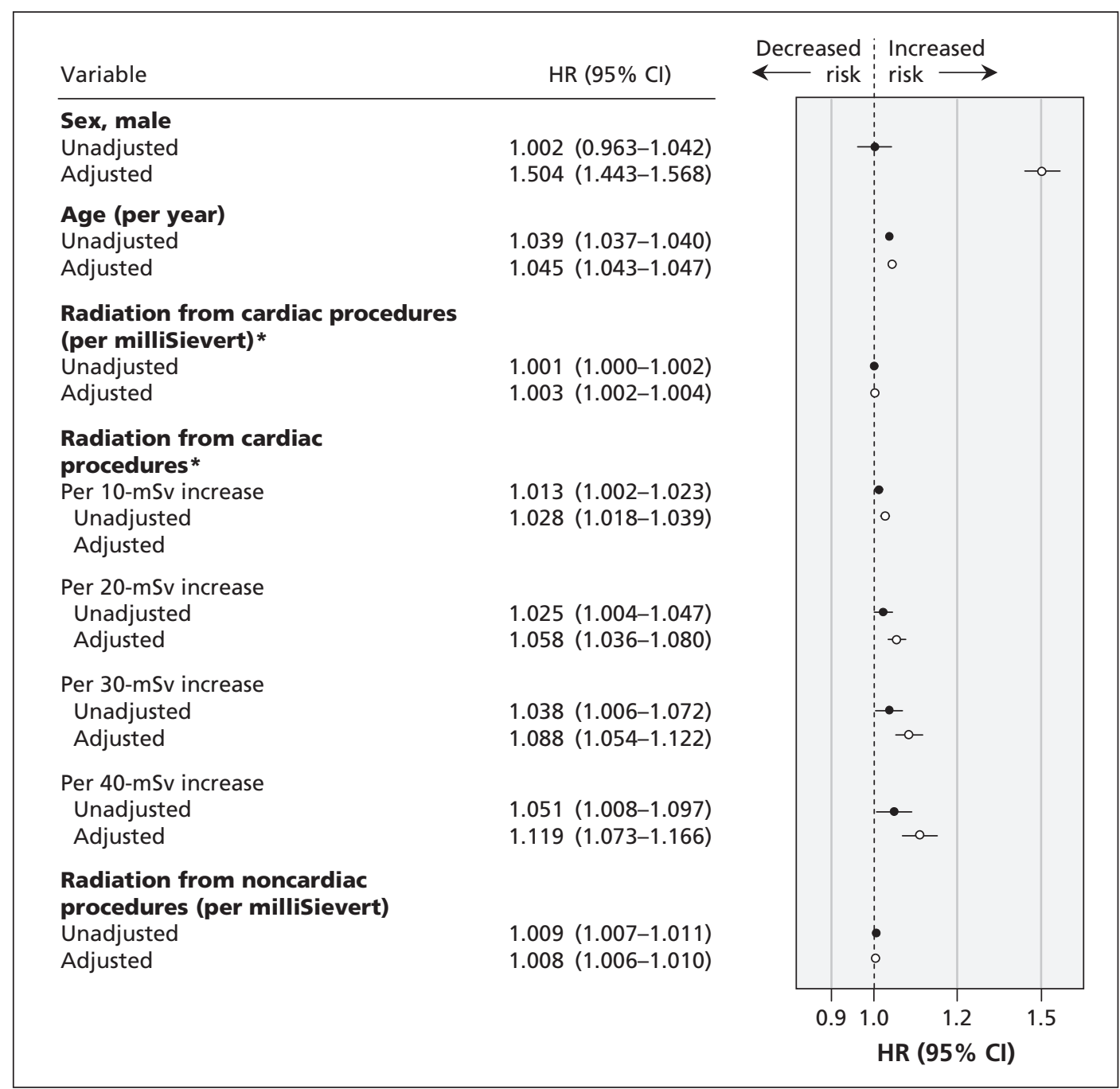

Figure 1: Relation between cumulative exposure to low-dose ionizing radiation (measured in milliSieverts) from cardiac imaging and therapeutic procedures after acute myocardial infarction and the risk of cancer during a mean follow-up period of $\mathbf{5 . 0}$ years. Hazard ratios (HRs) above 1.0 indicate an increased risk of cancer. Adjusted HRs were derived from models adjusted for age, sex and exposure to low-dose ionizing radiation from noncardiac procedures. *Among patients who were exposed to more than $0 \mathrm{mSv}$ of radiation. Note: $\mathrm{Cl}=$ confidence interval, $\mathrm{mSv}=$ milliSieverts. 
low-dose ionizing radiation increases their risk of cancer and perhaps mortality.

The potential increase in cancer-related death associated with exposure to radiation from cardiac imaging and therapeutic procedures has to be weighed against the potential risk of death from cardiovascular diseases for which these procedures are indicated and the resulting decrease in mortality expected with their use. Although we think that our results are important for identifying and quantifying possible harms, we also think that a valid evaluation to determine where the balance between these competing risks falls is not possible from our study, given its relatively short time horizon and the potential for residual confounding.

\section{Limitations}

A number of limitations of our study should be noted. First, we did not directly measure the doses of low-dose ionizing radiation in our cohort of patients. Instead, we used an administrative database to identify the cardiac imaging and therapeutic procedures that patients underwent and then used estimated doses ${ }^{7}$ to calculate the cumulative exposure for each patient. There is variability in these estimates. ${ }^{38,39}$ Technical aspects of these tests vary with the centre and operator, and perfect estimation of dose is not possible. We relied on a well-cited, recently published source to attempt to minimize this source of measurement error. ${ }^{7,29}$

Second, potential confounders entered into the models were limited to variables collected in the administrative database; therefore, there is a risk of residual confounding by indication. This risk is lowest for the association between exposure to radiation from cardiac procedures and cancer because cardiac imaging and therapeutic procedures are seldom indicated for the work-up of cancer, which makes it an ideal setting to test our hypothesis. The opposite is true for the association between exposure to radiation from noncardiac procedures and cancer (as supported by the HR observed in our model). Confounding by indication remains significant.

Third, we did not ascertain the difference between high, acute exposure to low-dose ionizing radiation after acute myocardial infarction and low, repeated exposure.

Fourth, we examined a cohort of patients who had acute myocardial infarction in Canada between 1996 and 2006. Canadian patients undergo fewer imaging and therapeutic procedures than American patients. ${ }^{40}$ Furthermore, the explosion of imaging techniques and therapeutic procedures has been rather recent. ${ }^{32,41}$ Thus, our cohort likely had lower levels of exposure to low-dose ionizing radiation than current patients with acute myocardial infarction in North America. Consequently, the numbers that we present may be underestimates of the level of exposure to radiation that current patients are experiencing.

\section{Conclusion}

We found that a substantial proportion of patients were exposed to high levels of low-dose ionizing radiation from cardiac imaging and therapeutic procedures after acute myocardial infarction. We were able to show that exposure to radiation from cardiac imaging was associated with an increased risk of cancer in this patient population. Even moderate levels of exposure were associated with an increased risk of cancer.

These results call into question whether our current enthusiasm for imaging and therapeutic procedures after acute myocardial infarction should be tempered. We should at least consider putting into place a system of prospectively documenting the imaging tests and procedures that each patient undergoes and estimating his or her cumulative exposure to low-dose ionizing radiation. $^{42}$

\section{References}

1. Brenner DJ, Doll R, Goodhead DT, et al. Cancer risks attributable to low doses of ionizing radiation: assessing what we really know. Proc Natl Acad Sci U S A 2003;100:13761-6.

2. Preston DL, Shimizu Y, Pierce DA, et al. Studies of mortality of atomic bomb survivors. Report 13: Solid cancer and noncancer disease mortality: 1950-1997. Radiat Res 2003;160:381-407.

3. Pierce DA, Preston DL. Radiation-related cancer risks at low doses among atomic bomb survivors. Radiat Res 2000;154:178-86.

4. Preston DL, Ron E, Tokuoka S, et al. Solid cancer incidence in atomic bomb survivors: 1958-1998. Radiat Res 2007;168:1-64.

5. Nakashima M, Kondo H, Miura S, et al. Incidence of multiple primary cancers in Nagasaki atomic bomb survivors: association with radiation exposure. Cancer Sci 2008;99:87-92.

6. Cardis E, Vrijheid M, Blettner M, et al. Risk of cancer after low doses of ionising radiation: retrospective cohort study in 15 countries. BMJ 2005;331:77.

7. Fazel R, Krumholz HM, Wang Y, et al. Exposure to low-dose ionizing radiation from medical imaging procedures. $N$ Engl $J$ Med 2009;361:849-57.

8. Smith-Bindman R, Miglioretti DL, Larson EB. Rising use of diagnostic medical imaging in a large integrated health system. Health Aff (Millwood) 2008;27:1491-502.

9. Bhargavan M, Sunshine JH. Utilization of radiology services in the United States: levels and trends in modalities, regions, and populations. Radiology 2005;234:824-32.

10. Bhargavan $\mathrm{M}$. Trends in the utilization of medical procedures that use ionizing radiation. Health Phys 2008;95:612-27.

11. Brenner DJ, Hall EJ. Computed tomography — an increasing source of radiation exposure. N Engl J Med 2007:357:2277-84.

12. Gerber TC, Carr JJ, Arai AE, et al. Ionizing radiation in cardiac imaging: a science advisory from the American Heart Association Committee on Cardiac Imaging of the Council on Clinical Cardiology and Committee on Cardiovascular Imaging and Intervention of the Council on Cardiovascular Radiology and Intervention. Circulation 2009;119:1056-65.

13. The 2007 recommendations of the International Commission on Radiological Protection. ICRP publication 103. Ann ICRP 2007; 37:1-332.

14. Wrixon AD. New ICRP recommendations. J Radiol Prot 2008; 28:161-8.

15. International Commission on Radiological Protection (ICRP). Radiation dose to patients from radiopharmaceuticals. Addendum 3 to ICRP Publication 53. ICRP Publication 106. Approved by the commission in October 2007. Ann ICRP 2008;38:1-197. 
16. Radiation protection in medicine. ICRP Publication 105. Ann ICRP 2007;37:1-63

17. Einstein AJ, Moser KW, Thompson RC, et al. Radiation dose to patients from cardiac diagnostic imaging. Circulation 2007;116: 1290-305.

18. Coles DR, Smail MA, Negus IS, et al. Comparison of radiation doses from multislice computed tomography coronary angiography and conventional diagnostic angiography. J Am Coll Cardiol 2006;47:1840-5

19. Einstein AJ. Radiation risk from coronary artery disease imaging: How do different diagnostic tests compare? Heart 2008;94:1519-21.

20. Hausleiter J, Meyer T, Hermann F, et al. Estimated radiation dose associated with cardiac CT angiography. JAMA 2009;301:500-7.

21. Henzlova MJ, Cerqueira MD, Hansen CL, et al. ASNC imaging guidelines for nuclear cardiology procedures: stress protocols and tracers. J Nucl Cardiol 2009;16:331.

22. Boice JD Jr, Preston D, Davis FG, et al. Frequent chest x-ray fluoroscopy and breast cancer incidence among tuberculosis patients in Massachusetts. Radiat Res 1991;125:214-22.

23. Ronckers CM, Doody MM, Lonstein JE, et al. Multiple diagnostic X-rays for spine deformities and risk of breast cancer. Cancer Epidemiol Biomarkers Prev 2008;17:605-13.

24. Kim KP, Einstein AJ, Berrington de GA. Coronary artery calcification screening: estimated radiation dose and cancer risk. Arch Intern Med 2009;169:1188-94.

25. Einstein AJ, Henzlova MJ, Rajagopalan S. Estimating risk of cancer associated with radiation exposure from 64-slice computed tomography coronary angiography. JAMA 2007;298:317-23.

26. Perisinakis K, Theocharopoulos N, Damilakis J, et al. Fluoroscopically guided implantation of modern cardiac resynchronization devices: radiation burden to the patient and associated risks. J Am Coll Cardiol 2005;46:2335-9.

27. Perisinakis K, Damilakis J, Theocharopoulos N, et al. Accurate assessment of patient effective radiation dose and associated detriment risk from radiofrequency catheter ablation procedures. Circulation 2001;104:58-62.

28. Pilote L, Lavoie F, Ho V, et al. Changes in the treatment and outcomes of acute myocardial infarction in Quebec, 1988-1995. CMAJ 2000; 163:31-6.

29. Mettler FA Jr, Huda W, Yoshizumi TT, et al. Effective doses in radiology and diagnostic nuclear medicine: a catalog. Radiology 2008;248:254-63.

30. Rachet B, Siemiatycki J, Abrahamowicz M, et al. A flexible modeling approach to estimating the component effects of smoking behavior on lung cancer. J Clin Epidemiol 2004;57:1076-85.

31. Lucas FL, DeLorenzo MA, Siewers AE, et al. Temporal trends in the utilization of diagnostic testing and treatments for cardiovascular disease in the United States, 1993-2001. Circulation 2006;113:374-9.

32. Alter DA, Stukel TA, Newman A. Proliferation of cardiac technology in Canada: a challenge to the sustainability of Medicare. Circulation 2006;113:380-7.

33. Morin DM, Lonstein JE, Stovall M, et al. Breast cancer mortality after diagnostic radiography: findings from the U.S. Scoliosis Cohort Study. Spine 2000;25:2052-63.

34. Ron E, Lubin JH, Shore RE, et al. Thyroid cancer after exposure to external radiation: a pooled analysis of seven studies. Radiat Res 1995;141:259-77.

35. Tu JV, Nardi L, Fang J, et al. National trends in rates of death and hospital admissions related to acute myocardial infarction, heart failure and stroke, 1994-2004. CMAJ 2009;180:E118-25.

36. Setoguchi S, Glynn RJ, Avorn J, et al. Improvements in longterm mortality after myocardial infarction and increased use of cardiovascular drugs after discharge: a 10-year trend analysis. $J$ Am Coll Cardiol 2008;51:1247-54.

37. Lloyd-Jones D, Adams R, Carnethon M, et al. Heart disease and stroke statistics - 2009 update: a report from the American Heart Association Statistics Committee and Stroke Statistics Subcommittee. Circulation 2009;119:e21-181.

38. Einstein AJ, Moser KW, Thompson RC, et al. Radiation dose to patients from cardiac diagnostic imaging. Circulation 2007;116: 1290-305.

39. Amis ES Jr, Butler PF, Applegate KE, et al. American College of Radiology white paper on radiation dose in medicine. $J$ Am Coll Radiol 2007;4:272-84.

40. Ayanian JZ. Rising rates of cardiac procedures in the United States and Canada. Too much of a good thing. Circulation 2006; 113:333-5.

41. Ko DT, Krumholz HM, Wang Y, et al. Regional differences in process of care and outcomes for older acute myocardial infarction patients in the United States and Ontario, Canada. Circulation 2007;115:196-203.

42. Mercuri M, Moran GR, Gauthier L, et al. Radiation dose in interventional cardiology procedures: urgent need for monitoring dose and establishing diagnostic reference levels. Healthc $Q$ 2008; 11:76-83.

Affiliations: From the Divisions of Cardiology and Clinical Epidemiology (Eisenberg, Afilalo), Jewish General Hospital, Montréal, Que.; the Faculty of Medicine (Eisenberg, Afilalo, Lawler, Pilote) and the Department of Epidemiology, Biostatistics and Occupational Health (Eisenberg, Abrahamowicz, Pilote), McGill University, Montréal, Que.; and the Division of Clinical Epidemiology (Abrahamowicz, Richard, Pilote) and the Division of Internal Medicine, Department of Medicine (Pilote), McGill University Health Centre, Montréal, Que.

Contributors: Mark Eisenberg and Louise Pilote were respondible for the study concept. Mark Eisenberg, Jonathan Afilalo, Patrick Lawler and Louise Pilote contributed to the study design and writing of the manuscript. Michal Abrahamowicz and Hugues Richard analyzed the data and revised the manuscript critically for important intellectual content. All of the authors approved the final version of the manuscript submitted for publication.

Funding: This study was funded in part by a grant from the Canadian Institutes of Health Research (grant no. MOP84304). Mark Eisenberg and Louise Pilote are National Researchers supported by the Fonds de la recherche en santé du Québec. Louise Pilote and Michal Abrahamowicz are James McGill Professors at McGill University.

Acknowledgements: The authors thank Kim Allan and Renée Atallah for their help in preparing the manuscript.

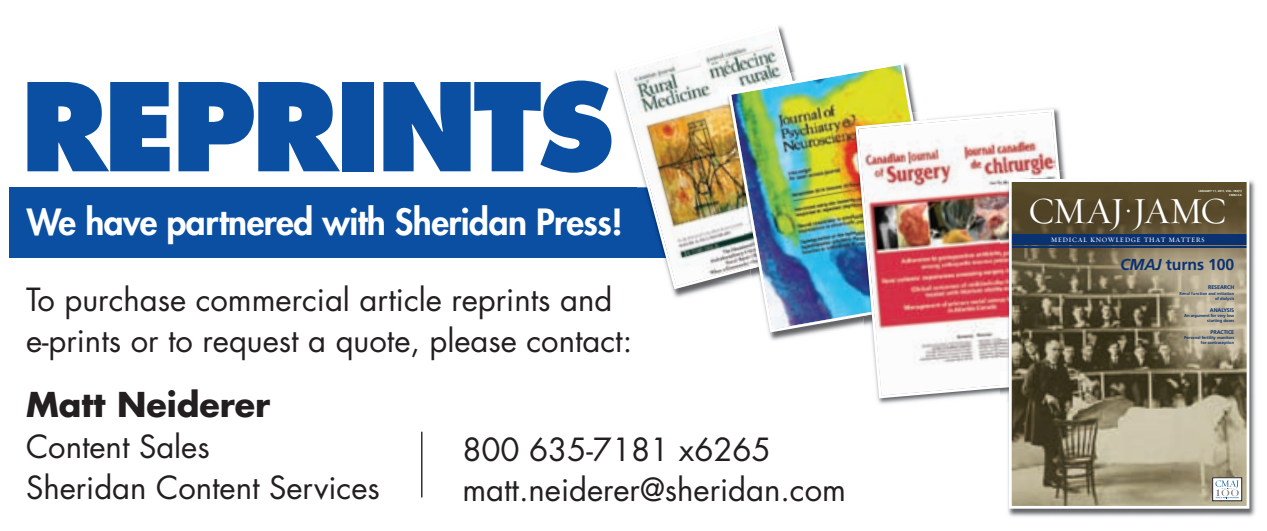

